\title{
Relationship between perceived discrimination and loneliness among transgender: Mediating role of coping mechanism
}

\section{Sadiq, Shahida $\bowtie$}

Department of Psychology, University of Sargodha, Sargodha, Pakistan (sadiqshahida@ymail.com)

Bashir, Aneeza

Department of Psychology, University of Sargodha, Sargodha, Pakistan (aneeza16@ gmail.com)

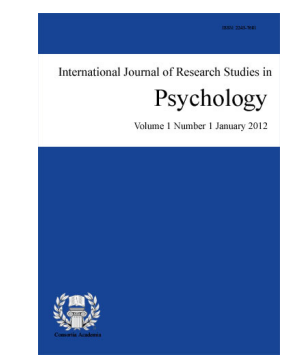

ISSN: 2243-7681 Online ISSN: 2243-769X

OPEN ACCESS

\section{Abstract}

This study examines exposure to perceived discrimination and its association with loneliness among transgender individuals as well as evaluates the mediating role of coping strategies. Total of 153 transgender individuals were recruited through community based organizations and referrals by snow ball sampling technique. Perceived discrimination was assessed by (Day to Day Life Perceived Discrimination Measure: Williams, Yu, Jackson, \& Anderson, 1997), presence of feelings of loneliness by (Loneliness and Social Dissatisfaction Scale: Asher et al. 1984) and coping strategies by (The Brief Cope Scale: Carver, 1997). Pearson correlation, linear and hierarchical regression was used to examine the association between perceived discrimination and loneliness and mediating role of coping strategies. A significant association between perceived discrimination and loneliness was identified. How exposure to discrimination leads to increased risk of loneliness and coping strategies mediate this relationship. The findings are helpful for mental health professional in treatment of minorities like transgender on the bases of coping strategies.

Keywords: transgender; perceived discrimination; loneliness and coping strategies 


\section{Relationship between perceived discrimination and loneliness among transgender: Mediating role of coping mechanism}

\section{Introduction}

The present study is proposed to find out relationship between perception of discrimination and loneliness among transgender and role of coping strategies. Transgender group most commonly encounters a wide variety of discriminatory attitude difficulties in meeting their basic needs or in having their gender identity respected. This discriminatory attitude towards transgender group is so invasive and destructive for their mental health.

Discrimination against an individual because of a perception that he or she has a protected characteristic when he or she does not, in fact, have that confined characteristic (Goto, Gee, \& Takeuchi, 2002). Perceptive discrimination is to claims of direct discrimination (Finch, Kolody, \& Vega, 2000). Discrimination refer to different components of group opposition when studying inter-group relations, that is, studying attitudes and behaviors exhibited by members of one group (the in-group) towards members of another group (the out-group) (Taylor, Peplau, \& Sears, 2000). Discrimination is defined as the behavioral component of group opposition when studying inter-group relations (Lee, Noh, Yoo, \& Sim-Doh, 2007). Perceived discrimination leads to feeling of loneliness and loneliness is a generally distasteful affecting reaction to separation or be deficient in of friendship. Typically Loneliness based on anxious way of thinking about a lack of companionship with other individual and it can be extended from present to future. Loneliness didn't mean numbers of people around person are lees it depend on quality of relationship with others. Loneliness is caused by variety of factors such as emotional, social and psychological factors (Peplau \& Perlman, 1982). John and William (2008) describes loneliness in term of social pain an emotional means to aware an person of segregation and encourage him/her to try to find social associations.

Research on loneliness indicated that discrimination in society caused loneliness and exclusion from society, and due to this discrimination and loneliness mental health declines (Thoits, 1982). Research findings suggest that loneliness is caused by social stressor and perception of discrimination (Hawkley, Hughes, Waite, Masi, Thisted, \& Cacioppo, 2008). People who are discriminated at work place, discrimination work as stressor that leads them to loneliness (Forman, 2003). Exposure of discrimination in everyday life causes feeling of loneliness (Feagin \& McKinney 2003). Clark, Anderson, Clark, and Williams (1999) researches findings indicate that every day discrimination linked with three indicator of mental health as discrimination work as stressor, persistent and negative effect on mental health and finally leads to loneliness (Williams \& Mohammed 2009). A longitudinal study suggested that there is a causal relationship between perception of discrimination and mental health (Brown, Williams, Jackson, Neighbors, Torres, Sellers, \& Brown, 2000; Pavalko, Mossakowski, and Hamilton 2003). This research examines the link between perceived discrimination and loneliness (Schultz, Gravlee, Williams, Israel, Mentz, \& Rowe, 2006). Study examined discrimination has significant positive relationship with to poor adjustment like loneliness (Juang \& Alvarez, 2010).

Coping styles refers to most common most recurrent, and longer term style of coping that an individual tend to use across a variety of situations (Schou, Ekeberg, \& Ruland, 2004). Coping mechanism is described as strategies or efforts used to manage, minimize, and learn to deal with harmful situations that cause worries or alleviate or stand for psychosomatic health problems (Folkman \& Lazarus, 1980). Coping is an adoptive function which effort to minimize problems with self and with social relations and deal with conflicts (Weiten \& Lloyd, 2008).

Liang, Alvarez, Juang, and Liang, (2007) found that coping work as mediator between perception of discrimination and mental health is also positively related with stress. Alvarez and Juang (2010) study demonstrated that coping strategies mediate between the relationships of discrimination decline of mental health 
out of previous studies, measured general coping styles (Wei, Ku, Russell, Mallinckrodt, \& Liao, 2008).

Scholars noted that while some people may only be slightly bothered by discrimination incidents, others may remember in great detail and feel extremely bothered by perceived discrimination in their present lives (Thompson-Miller \& Feagin, 2007). Along this line, Clark et al. (1999) examined factors that or mediates the effects of perceived discrimination such as coping strategies. Wei, Heppner, Ku, and Liao (2010) suggested that the relationship of discrimination related stress and decline in mental fitness can understand by examining coping. In a coping process, individuals use specific coping strategies, and these coping strategies mediate the relationship of stress due to discrimination and psychological modification difficulties (Liang, Nathwani, Ahmad, \& Prince, 2010). Among lesbian, gays, bisexual and transgender persons, studies of social support have found both direct and stress-buffering effects on mental health (Szymanski, Chung, \& Balsam, 2001) found that spirituality has been directly linked with adjustment and positive mental health (Lease, Horne, \& Noffsinger-Frazier, 2005). Such psychological resources may thus mediate the relationship between stressors and health (lazarus, 1999).

Coping strategies can mediate the relationship of discrimination as a stressor and mental health problems. Borders and Liang (2011) also examined that coping strategies work as mediator between perceived discrimination and in psychological problems. Clark, Anderson, Clark, and Williams (1999) perspective is consistent with the conceptualization of stressor and on Lazarus and Folkman's (1984) stress coping model that described coping as a mediator between perception of discrimination and mental health problems. Findings from these two studies are contrary to the expectations of a traditional stress-coping framework, in which commitment coping is commonly related with lower stress, study results demonstrated that avoidant coping have mediating relationship between perception of discrimination and depressive symptoms among minorities (Eleanor, Upton, Gilbert, \& Volpe, 2013).

The purpose of present investigation closely study perceived discrimination that predicts loneliness in transgender. Perceived discrimination is a life stressor and as such has influences on loneliness. Further this study will explore whether coping strategies play mediating between perception of discrimination and loneliness among transgender. This study is first one that was conducted with transgender by birth as a quantitative research in Pakistan. Previous researches are either qualitative or comprised sample cross dresser and eunuch. Based on the previous studies and researches, following hypotheses are formulated:

$>$ Perceived discrimination will be positively associated with loneliness among transgender.

$>\quad$ Coping mechanism will play mediating role between perceived discrimination and loneliness among transgender.

\section{Method}

\subsection{Participants}

The sample of the study was $\mathrm{N}=153$ individuals, Gurus $13.7 \%(n=21)$ and Chelas $86.3 \%(n=132)$ age range from 16-81 $(M=36.84, S D=15.71)$ which are by birth transgender (hijras). The sample was comprised of transgender individuals collected from twenty one cities of Punjab as Jarhanwala, Phalia, Laaya, Bhalwal, Dinga, Mandi-bahaudin, Samundary, Parhiyanwali, Lalamosa, Bhakhar, Gujrat, Mongowal, Malikwal, Gujranwala, Kharian, Jehlam, P. D. Khan, Wazir-abad, Rawalpindi, Islamabad and Faisalabad. Sample was approached for data collection in their communities through snow ball sampling. The following inclusion criteria were used for inclusion in the research sample: Any age range individual's transgender by birth, living within communities of transgender, education level is not necessary, willingness to participate in the current research project with or without money. The following exclusion criteria were used for exclusion in the research sample: Transgender by adoptive profession, transgender by choice, individual with gender identity disorder and Individual living with 
Sadiq, S., \& Bashir, A.

their families.

\subsection{Instruments}

Everyday Discrimination Scale - The everyday discrimination scale was used developed by Williams, Yu, Jackson, and Anderson (1997) translated by Sadiq (2014) to measure perception of discrimination of participants that takes place in daily life. The Everyday Discrimination Scale eliminates the option of socially desirable responses of measures. The original measure included nine items. Response format of scale was 6-point Likert scale range from 1 (never), 2 (once a year), 3 (many times a year), 4 (many times a month), 5 (once a week) and 6 (daily) from 0 (did not apply to me at all) to 3 (applied to me very much, or most of the time). Reliability ( $\alpha=.91$ ) scores indicate this scale measure the perception of discrimination and high score reflects high discrimination and low score indicates low discrimination experienced by sample. Score range is 0 to 54 .

Loneliness and Social Dissatisfaction Scale - To measure presence of feelings of loneliness, Loneliness and Social Dissatisfaction Scale (LSDS; Asher, Hymel, \& Renshaw, 1984) translated by Tariq and Masood (2011) was used. LSDS consisted of 24 items, 16 item measures feelings of loneliness and 8 items are filler items that find out interest and activities. Response format of LSDS was a 5-point rating ranging from 1 (not at all true), 2 (at some extent wrong), 3 (at some extent true), 4 (mostly true) and 5 (Always true). A total score is obtained by summing all items which assess loneliness excluding filler items. Filler items are scale (items 2, 5, 7, 11, 13, 15, 19, and 22) and reverse-coded Items are (1, 3, 4, 8, 10, 14, 16, 18, 21, and 23). Item no 20 omitted and didn't include in original scores. Total scores range from 15 to 75 and High score on LSDS was indicative of more feelings of loneliness while low score reflect lesser experience of loneliness. Internally consistency of LSDS was $($ Cronbach's $=.90)$ and split-half reliability was $=.83$ reported by the original authors (Asher, Hymel, \& Renshaw, 1984).

Brief Cope Scale - The Brief Cope Scale, originally developed by Carver (1997) and translated into Urdu by Akhtar (2005) was used to recognizing the coping styles. Brief Cope Scale is a brief form of Cope Inventory (Carver, Scheier, \& Weintraub, 1989). In the present research factor structure of Hastings et al. (2005) for Brief Cope (Carver, 1997) is used. He reported four subscales for Brief Cope namely: Problem Focused Coping Strategies, Positive Coping strategies, Active/Avoidance Coping strategies and Religious/Denial Coping strategies. Active/Avoidance coping include items from the original Brief Cope (item no. 1, 4, 6, 9, 11, 13, 16, 19, 21 and 26), Problem focused coping (item no. 2, 5, 7, 10, 14, 23 and 25), Positive coping (item no. 12, 15, 17, 18, 20, 24 and 28) and Religious/Denial coping strategy (item no. 3, 8, 22 and 27). The items are summed for each subscale separately to get a total score on all 4 categories. The high score on each subscale indicate more use of that specific coping style and low scores indicate a less amount of use of that coping strategy.

\subsection{Research Design}

Current cross-sectional survey research is aimed to check the link between perception of discrimination and loneliness among transgender; role of coping mechanism.

\subsection{Procedure}

Before data collection special permission letter was signed Chairperson, psychology department, University of Sargodha. First of all we consulted at head office of transgender individuals at Rawalpindi with the help of (In-charge correspondence express media group Islamabad). Purpose and advantages was clearly communicated with heads of specified communities. After obtaining the permission, individuals were personally approached Questionnaire along with Demographic Form was administered after obtaining written informed consent. Informed consent included purpose of research, procedure and their rights as participants, and confidentiality of the data was assured to the sample. Clear instructions were given to all the participants about the instruments and response format, written booklet of the questionnaires was provided to the participants and participants who have reading difficulty or could not read that questionnaire were interviewed and after interview questionnaires were 
marked according to their. After administration of questionnaire individuals were paid money by according to their demands. Data collection was completed in 6 month.

\section{Results}

\subsection{Test of Relationship among Variable of Study}

Pearson product moment correlations were calculated to see how the variables of the study were related in the sample of transgender. Table 1 displays the correlation between variable of study

\section{Table 1}

Descriptive and Relationship between variables of study among transgender $(N=153)$

\begin{tabular}{|c|c|c|c|c|c|c|c|}
\hline \multicolumn{2}{|c|}{ Variables } & 1 & 2 & 3 & 4 & 5 & 6 \\
\hline 1 & EDM & . & $.17^{*}$ & .11 & $.16^{*}$ & $.24^{* * * *}$ & -.01 \\
\hline 2 & LS & & - & -.12 & .16 & $.21^{* * *}$ & -.11 \\
\hline 3 & A/ACS & & & - & -.04 & -.13 & $.36^{* * * *}$ \\
\hline 4 & PFCS & & & & - & $.60^{* * *}$ & .02 \\
\hline 5 & PCS & & & & & - & .06 \\
\hline 6 & $\mathrm{R} / \mathrm{DCS}$ & & & & & & - \\
\hline & Mean & 42.06 & 48.63 & 22.69 & 19.01 & 19.37 & 10.22 \\
\hline & SD & 10.42 & 12.83 & 5.20 & 4.45 & 4.66 & 2.71 \\
\hline & $\alpha$ & .94 & .91 & .67 & .74 & .78 & .56 \\
\hline
\end{tabular}

Note. PDM = day to day life perceived discrimination measure; $\mathrm{LS}=$ loneliness scale; AACS = active/avoidance coping scale; PFCA = problem-focused coping scale; $\mathrm{PCS}=$ positive coping scale; R/DCS = religious/denial coping scale.

$* * * p<.001 * p<.05$

Table 1 shows mean, standard and internal satisfactory index (alpha coefficient) of all the scales that used in present study. The reliability analysis revealed that reliability coefficient of day to day life perceived discrimination measure, Loneliness Scale, Brief Cope Scale, A/A Coping Scale, PF Coping Scale, PC Scale, R/D Coping Scale, Depression Scale, Anxiety Scale and Stress Scales is .94, 91, .92, .67, .74, .78, .56, and .91 respectively which indicates satisfactory internal consistency. Religious/Denial Coping Scale has Alpha reliability value .56 this subscale consisted on 4 items scale as two items of religious subscale and two items of denial subscale. Finding indicates that perceived discrimination was significantly correlated with loneliness, problem focused coping and positive coping scale has non-significant correlation with active/avoidance coping scale and religious/denial coping scale. Result of perceived discrimination are significant and positively correlated with loneliness scale and problem focused coping at .05 level $\left({ }^{*} p<.05\right)$ and positive coping scale, at 0.001 level $(* * * p<.001)$

\subsection{Linear Regression Analysis}

Linear regression analysis was conducted to measure effect of independent variables, to predict loneliness; results are presented in table 2

\section{Table 2}

Regression analysis for Perceived Discrimination Predicting Loneliness among Transgender $(N=153)$.

\begin{tabular}{lccccc}
\hline Predictor Variables & $B$ & $S E B$ & $\beta$ & $T$ & $p$ \\
\hline PDM & .21 & .09 & .172 & 2.14 & .034 \\
\hline
\end{tabular}

Note. $\mathrm{PDM}=$ day to day life perceived discrimination.

$* * * p<.001 \quad * p<.05$

Table 2 demonstrates the analysis of simple regression for perceived discrimination as a predictor of loneliness among transgender $\{F(1,151)=4.58, p<.05\}$. Results indicates that $\operatorname{PDM}(\beta=.172, t=2.14, p$ $=.034)$ is significant predictor of loneliness among transgender and table also demonstrated $3 \%$ variance in loneliness that could be attributed to $\operatorname{PDM}\left(R^{2}=.03\right)$. 
Sadiq, S., \& Bashir, A.

\subsection{Hierarchical Regression for Mediating Analysis}

Hierarchical regression analyses was done for predicting mediating role of positive coping strategy and results are presented in table 3

\section{Table 3}

Hierarchical Regression for Positive Coping Mediating the Relationship between Perceived Discrimination and Loneliness $(N=153)$

\begin{tabular}{lcc}
\hline \multicolumn{1}{c}{ Predictors } & $\Delta \mathrm{R}^{2}$ & $\mathrm{~B}$ \\
\hline Step I & .03 & $.17^{*}$ \\
$\begin{array}{l}\text { Perceived discrimination } \\
\text { Step II }\end{array}$ & .05 & .13 \\
Perceived discrimination & & $.18^{*}$ \\
Positive Coping & & \\
Total $R^{2}$ & .08 & \\
\hline Note. $* * p .01 \quad * p<.05$ & &
\end{tabular}

Table 3 depicts meditating effect of positive coping in relation between perceived discrimination and loneliness. Baron and Kenny (1986) guidelines are used to test the mediation which displays significant results such as for first condition perceived discrimination is showing significant prediction of loneliness $\left(\beta=.17^{*}, t=\right.$ $2.14, p<.034)$ at $\left\{\left(R^{2}=.03\right) F(1,151)=4.58, p<.034\right\}$ with $3 \%$ variance in loneliness. Second condition is tested in which positive coping is significantly predicting loneliness in positive direction $(\beta=.18, t=2.22, p$ $<.05)$. This model shows additional variance of $3 \%$ in loneliness $\left\{\Delta R^{2}=.03, \Delta F(1,150)=4.94, p<.01\right\}$. For the last condition prediction of positive coping by perceived discrimination also found to be positively significant $(\beta$ $=.24, t=3.03, p<.01)$ at $\left\{\left(R^{2}=.06\right) . F(1,151)=9.16, p<.01\right\}$ with $6 \%$ variance in positive coping. The final evidence of mediation is evident as perceived discrimination becomes non-significant predictor of loneliness when positive coping was entered into the model. Therefore results indicated that positive coping fully mediated the relationship between perceived discrimination and loneliness. This meditational model is further ascertained on the basis of Sobel's test (1986) for assessing the significance of mediation which proved to be significant with $25.1 \%$ of the variance in loneliness explained by perceived discrimination is attributable to the meditational effect of positive coping. The positive coping is mediating the relationship between perceived discrimination and loneliness and indirectly predicting loneliness (Sobel's $Z=1.80, p<.05$ ).

\subsection{Difference among Gurus and Chelas among Variables of Study (Additional analysis)}

Mean standard deviation and $t$-values for Gurus and Chelas on day to day life perceived discrimination measure, loneliness scale, active/avoidance coping scale, problem-focused coping scale, positive coping scale and religious/denial coping scale are presented in table 4 .

\section{Table 4}

Mean, Standard Deviation, \& $t$-values of Gurus and Chelas on Variables of Present study $(N=153)$

\begin{tabular}{|c|c|c|c|c|c|c|c|c|c|}
\hline \multirow{2}{*}{ Variable } & \multicolumn{2}{|c|}{ Guru $(n=21)$} & \multicolumn{2}{|c|}{ Chelas $(n=132)$} & \multirow{2}{*}{$t(151)$} & \multirow{2}{*}{$p$} & \multicolumn{2}{|c|}{$95 \% \mathrm{CI}$} & \multirow{2}{*}{$\begin{array}{c}\text { Cohen's } \\
d\end{array}$} \\
\hline & $M$ & $S D$ & $M$ & $S D$ & & & $L L$ & $U L$ & \\
\hline PDM & 40.24 & 11.85 & 42.35 & 10.20 & -.86 & .390 & -6.95 & 2.73 & -.20 \\
\hline LS & 48.95 & 12.99 & 48.58 & 12.85 & .12 & .903 & -5.60 & 6.342 & .03 \\
\hline AACS & 20.29 & 4.23 & 23.08 & 5.26 & -2.31 & .022 & -5.17 & -.41 & -.58 \\
\hline PFCS & 22.38 & 3.92 & 18.48 & 4.31 & 3.90 & .000 & 1.93 & 5.88 & .95 \\
\hline PCS & 22.57 & 4.06 & 18.86 & 4.56 & 3.52 & .001 & 1.63 & 5.80 & .86 \\
\hline RDCS & 10.10 & 3.06 & 10.24 & 2.66 & -.230 & .818 & -1.41 & 1.12 & .94 \\
\hline
\end{tabular}


Result indicates significant mean differences on active/avoidance coping with $t(153)=-2.31, p<.05$, problem-focused coping with $t(153)=3.90, p<.001$, positive coping with $t(153)=3.52, p<.01$ and non-significant mean differences on perceived discrimination, loneliness and religious/denial coping. It indicates Gurus Experience high level of problem focused coping and positive coping than Chelas on the other hand Chelas experience high level of active/avoidance coping than Gurus. But level of experiencing perceived discrimination, loneliness, religious/denial coping for Gurus and Chelas is same.

\section{Discussion}

The study was aimed at examine the association between perception of discrimination and loneliness, role of beliefs in a just world and coping strategies among transgender. Overall findings suggested the perceived discrimination predicts loneliness. Coping strategies play mediating role between perceived discrimination and psychological health variables loneliness.

Present study was carried out to find out the connection between perception discrimination and psychological health variables loneliness. Our first hypothesis was accepted as perceived discrimination has positive significant correlation with loneliness. Findings indicate inter-scale correlation revealed that perception of discrimination and loneliness has significant relationship (see table 1). The first objective of current research was to study the relationship of perception of discrimination and loneliness. Relational hypothesis was made in order to meet this goal. The hypothesis stated that there would be positive relationship between perceived discrimination and loneliness among transgender. Pearson correlation was used to test this hypothesis. This hypothesis was accepted as analysis shows significant positive correlation. On the basis of these findings our hypothesis was accepted (see table $1 \& 2$ ). Previous studies on perception of discrimination among transgender individuals also support our findings as experience of discrimination is a predictor of loneliness as it produce a heightened stress response, which is linked with unhealthy behaviors patterns pessimistic thoughts (hopelessness), as well as decreased participation in healthy behaviors socialization like loneliness (Pascoe \& Richman, 2009). Study on perception of discrimination and loneliness indicates perception of discrimination is linked with stress that leads to social isolation (Liebkind \& Jasinskaja, 2000). Clark, Coleman, and Novak (2004) described that perception of discrimination has positive relationship with internalizing problems (stress, depression, anxiety and loneliness) support our findings (see table $1 \& 2$ ).

The aim of the present study was to investigate coping strategies mediating role between perceived discrimination and mental health variable as loneliness. It was hypothesized that coping strategies has mediating role between perceived discrimination and mental health. Hierarchical regression analysis has carried out. Result revealed that positive coping mediate the relationship between perception of discrimination and loneliness. Therefore results indicated that positive coping fully mediated the relationship between perceived discrimination and loneliness (see table 3). Our hypothesis partial accepted as only positive coping mediate the relation between perceived discrimination and loneliness and partially rejected as other coping strategies active avoidance coping, problem focused coping and religious coping didn't mediate this relationship. Previous research support our hypotheses accepted hypotheses studies examined coping as mediators. Liang, Alvarez, Juang, \& Liang, (2007) found that coping was a mediator that was positively associated with poor mental health. Alvarez and Juang (2010) found that coping was negatively associated with psychological distress. Out of previous studies, measured general coping styles (Wayment \& Peplau, 1995) and the remaining studies investigated situation specific coping in the relationship between perceived racism and depressive symptoms or psychological distress and this relationship of coping mediate between discrimination and poor health outcomes or psychological distress.

\section{Conclusion and Implications of the study}

It is concluded that perceived discrimination has significant positive relationship loneliness. The overall findings suggest that greater the perceived discrimination is the predictor of higher loneliness, positive coping 
Sadiq, S., \& Bashir, A.

mediating the relationship between perceived discrimination and loneliness. Furthermore, it was found that Gurus Experience high level of problem focused coping and positive coping than Chelas on the other hand Chelas experience high level of active/avoidance coping than Gurus. But level of experiencing perceived discrimination, loneliness, religious/denial coping for Gurus and Chelas is same. The findings are helpful for mental health professional in treatment of minorities like transgender on the bases of coping strategies. Professionals can use their coping behavior to mediate the effect of stressor of life like perceived discrimination, and how they utilize their strengths and change their cognitive thoughts to survive in society. Health professionals can integrate belief system with coping strategies to lessen the harm of discrimination.

\subsection{Limitations of study and suggestions}

Certain issues that could not be controlled can weaken the results of the study. A brief discussion of all these is mentioned here: There is a lack of data and other verification about the transgender residents at nationwide and local levels. There is no practically precise estimation of the size of the transgender population and the significant assortment within this society. It is restriction to make vigorous population generalizations from the quantitative studies to date. This is self-funded project and by considering its cost and resources sample size was small. There are substantial troubles inherent in the study of transgender populations, recognizing transgender individuals and compliant transgender sub-groups in surveys can be complicated.

Keeping in view the current issues of contaminating the present research, some suggestions for future research are recommended: Further longitudinal research should conducted to make inference on cause effect relationship, including multiple indicators of perceived discrimination and mental wellbeing expending diversity of transgender sample. Further research should be studies to measures the attitude of educational institutions, why the literacy rate is low in transgender communities, either situation is due to administration of institutions, teachers, or other reasons.

\section{References}

Akhtar, M. (2005). Student life stress and its relationship with time management and adopted coping strategies. Unpublished M. Phil thesis, National Institute of Psychology, Quaid-i- Azam University, Islamabad, Pakistan.

Alvarez, A. N., \& Juang, L. P. (2010). Filipino Americans and racism: A multiple mediation model of coping. Journal of Counseling Psychology, 57(2), 167-178. http://dx.doi.org/10.1037/a0019091

Asher, S. R., Hymel, S., \& Renshaw, P. D. (1984). Loneliness in children. Child Development, 55(4), 1456-1464. http://dx.doi.org/10.2307/1130015

Baron, R. M., \& Kenny, D. A. (1986). The moderator-mediator variable distinction in social psychological research: Conceptual, strategic and statistical considerations. Journal of Personality and Social Psychology, 51(6), 1173-1182. http://dx.doi.org/10.1037/0022-3514.51.6.1173

Borders, A., \& Liang, C. H. (2011). Rumination partially mediates the associations between perceived ethnic discrimination, emotional distress and aggression. Cultural Diversity and Ethnic Minority Psychology, 17(2), 125-133. http://dx.doi.org/10.1037/a0023357

Brown, T. N., Williams, D. R., Jackson, J. S., Neighbors, H. W., Torres, M., Sellers, S. L., \& Brown, K. T. (2000). Being black and feeling blue: The mental health consequences of racial discrimination. Race and Society, 2, 117-131. http://dx.doi.org/10.1016/S1090-9524(00)00010-3

Carver, C. S. (1997). You want to measure coping but your protocol's too long: Consider the brief cope. International Journal of Behavioral Medicine, 4, 92-100. http://dx.doi.org/10.1207/s15327558ijbm0401_6

Carver, C. S., Scheier, M. F., \& Weintraub, J. K. (1989). Assessing coping strategies: A theoretically based approach. Journal of Personality and Social Psychology, 56(2), 267-283. http://dx.doi.org/10.1037/0022-3514.56.2.267

Clark, R., Anderson, N. B., Clark, V. R., \& Williams, D. R. (1999). Racism as a stressor for African Americans: 
A bio-psycho-social model. American Psychologist, 54, 805-816. http://dx.doi.org/10.1037/0003-066X.54.10.805

Clark, R., Coleman, A. P., \& Novak, J. D. (2004). Brief report: Initial psychometric properties of the everyday discrimination scale in black adolescents. Journal of Adolescence, 27, 363-368. http://dx.doi.org/10.1016/j.adolescence.2003.09.004

Eleanor, K. S., Upton, R., Gilbert, A., \& Volpe, V. (2013). A moderated mediation model: Racial discrimination, coping strategies and racial identity among black adolescents. Child Development, 85(3), 882-890.

Feagin, J, R. \& McKinney, K. D. (2003). The many costs of racism. Lanham, MD: Rowman \& Littlefield;

Finch, B. K., Kolody, B., \& Vega, W. A. (2000). Perceived discrimination and depression among Mexican origin adults in California. Journal of Health and Social Behavior, 41(3), 295-313. http://dx.doi.org/10.2307/2676322

Folkman, S., \& Lazarus, R. S. (1980). An analysis of coping in a middle-aged community sample. Journal of Health and Social Behavior, 21(3), 219-239. http://dx.doi.org/10.2307/2136617

Forman, T. A. (2003). The Social psychological costs of racial segmentation in the workplace: A study of African Americans' wellbeing. Journal of Health and Social Behavior, 44, 332-352. http://dx.doi.org/10.2307/1519783

Goto, S. G., Gee, G. C., \& Takeuchi, D. T. (2002). Strangers still: The experience of discrimination among Chinese Americans. Journal of Community Psychology, 30(2), 211-224. http://dx.doi.org/10.1002/jcop.9998

Hastings, P. D., Rubin, K. H., \& DeRose, L. M. (2005). Links among gender, inhibition and parental socialization in the development of pro-social behavior. Merrill-Palmer Quarterly, 51, 501-527. http://dx.doi.org/10.1353/mpq.2005.0023

Hawkley, L. C., Hughes, M. E., Waite, L. J., Masi, C. M., Thisted, R. A., \& Cacioppo, J. T. (2008). From social structural factors to perceptions of relationship quality and loneliness: The Chicago health, aging, and social relations study. The Journals of Gerontology Series B: Psychological Sciences and Social Sciences, 63, 375-384. http://dx.doi.org/10.1093/geronb/63.6.S375

John, C., \& William, M. P. (2008). Loneliness: Human nature and the need for social connection. New York: W.W. Norton \& Co.

Juang, L. P., \& Alvarez, A. A. (2010). Discrimination and adjustment among Chinese American adolescents: Family conflict and family cohesion as vulnerability and protective factors. American Journal of Public Health, 100(12), 2403-2409. http://dx.doi.org/10.2105/AJPH.2009.185959

Larson, R. (1999). The uses of loneliness in adolescence. In K. J. Rotenberg \& H. Shelley (Eds.), Loneliness in childhood and adolescence (pp. 244-262). Cambridge, UK: Cambridge University Press. http://dx.doi.org/10.1017/CBO9780511551888.012

Lazarus, R. S., \& Folkman, S. (Eds.) (1984). Stress, appraisal and coping. New York, NY: Springer.

Lease, S. H., Horne, S. G., \& Noffsinger-Frazier, N. (2005). Affirming faith experiences and psychological health for Caucasian lesbian, gay, and bisexual individuals. Journal of Counseling Psychology, 52, 378-388. http://dx.doi.org/10.1037/0022-0167.52.3.378

Lee, R. M., Noh, C. Y., Yoo, H. C., \& Sim-Doh, H. S. (2007). The psychology of Diaspora experiences: Intergroup contact, perceived discrimination, and the ethnic identity of Koreans in China. Cultural Diversity and Ethnic Minority Psychology, 13(2), 115-124. http://dx.doi.org/10.1037/1099-9809.13.2.115

Liang, C. T. H., Alvarez, A. N., Juang, L. P., \& Liang, M. X. (2007). The role of coping in the relationship between perceived racism and racism-related stress for Asian Americans: Gender differences. Journal of Counseling Psychology, 54, 132-141. http://dx.doi.org/10.1037/0022-0167.54.2.132

Liang, C. T. H., Nathwani, A., Ahmad, S., \& Prince, J. K. (2010). Coping with discrimination: The subjective well-being of South Asian American women. Journal of Multicultural Counseling and Development, 38 , 77-87. http://dx.doi.org/10.1002/j.2161-1912.2010.tb00116.x

Liebkind, K., \& Jasinskaja, I. (2000). The influence of experiences of discrimination on psychological stress: A comparison of seven immigrant groups. Journal of Community and Applied Social Psychology, 10(1), 
Sadiq, S., \& Bashir, A.

1-16. http://dx.doi.org/10.1002/(SICI) 1099-1298(200001/02)10:1<1::AID-CASP521>3.0.CO;2-5

Pascoe, E. A., \& Richman, L. S. (2009). Perceived discrimination and health: A meta-analytic review. Psychological Bulletin, 135(4), 531-554. http://dx.doi.org/10.1037/a0016059

Pavalko, E. K., Mossakowski, K. N., \& Hamilton, V. J. (2003). Does perceived discrimination affect health? longitudinal relationships between work discrimination and women's physical and emotional health. Journal of Health and Social Behavior, 44, 18-33. http://dx.doi.org/10.2307/1519813

Peplau, L. A.; Perlman, D. (1982). Perspectives on loneliness. In L. A. Peplau, D. Perlman, (Eds.). Loneliness: A sourcebook of current theory, research and therapy (pp. 1-18). New York: John Wiley \& Sons.

Ross, M., \& Miller, D. T. (Eds.) (2002). The justice motive in everyday life. Cambridge UK: Cambridge University Press. http://dx.doi.org/10.1017/CBO9780511499975

Schou, I., Ekeberg, T., \& Ruland, C. M. (2004). Pessimisms as a predictor of emotional morbidity trait in youth and subsequent development of cancer among physicians. Journal of Behavioral Medicine, 43, $117-125$.

Schultz, A. J., Gravlee, C. C., Williams, D. R., Israel, B. A., Mentz, G., \& Rowe, Z. (2006). Discrimination, symptoms of depression, and self-rated health among African American women in Detroit: Results from a longitudinal analysis. American Journal of Public Health, 96, 1265-1270. http://dx.doi.org/10.2105/AJPH.2005.064543

Sadiq, S. (2014). Relationship between perceived discrimination and mental health: Role of coping mechanism and belief in just world among transgender in Punjab. Unpublished M. Phil Dissertation, University of Sargodha, Sargodha, Pakistan.

Sobel, M. E. (1982). Asymptotic intervals for indirect effects in structure equation models. In S. Leinhart (Ed.). Sociological methodology (pp. 290-312). San Francisco: Jossey-Bass.

Szymanski, D. M., Chung, Y. B., \& Balsam, K. F. (2001). Psychosocial correlates of internalized homophobia in lesbians. Measurement and Evaluation in Counseling and Development, 34, 27-38.

Tariq, T., \& Masood, S. (2011). Social competence, parental promotion of peer relations, and loneliness among adolescents. Pakistan Journal of Psychological Research, 26(2), 217-232.

Taylor, S. E., Peplau, L. A., \& Sears, D. O. (2000). Social Psychology. New Jersey: Prentice Hall, Inc.

Thoits, P. A. (1982). Conceptual, methodological and theoretical problems in studying social support as a buffer against life stress. Journal of Health and Social Behavior, 23(2), 145-159. http://dx.doi.org/10.2307/2136511

Thompson-Miller, R., \& Feagin, J. R. (2007). Continuing injuries of racism: Counseling in a racist context. The Counseling Psychologist, 35, 106-115. http://dx.doi.org/10.1177/0011000006294664

Wayment, H. A., \& Peplau, L. A. (1995). Social support and well-being among lesbian and heterosexual women: A structural modeling approach. Personality and Social Psychology Bulletin, 21, 1189-1199. http://dx.doi.org/10.1177/01461672952111007

Wei, M., Heppner, P. P., Ku, T.-Y., \& Liao, K. Y.-H. (2010). Racial discrimination stress, coping and depressive symptoms among Asian Americans: A moderation analysis. Asian American Journal of Psychology, 1 , 136-150. http://dx.doi.org/10.1037/a0020157

Wei, M., Ku, T.-Y., Russell, D. W., Mallinckrodt, B., \& Liao, K. Y.-H. (2008). Moderating effects of three coping strategies and self-esteem on perceived discrimination and depressive symptoms: A minority stress model for Asian international students. Journal of Counseling Psychology, 55, 451-462. http://dx.doi.org/10.1037/a0012511

Weiten, W., \& Lloyd, M. A. (2008). Psychology applied to modern life (9th ed.). Wadsworth engages Learning.

Williams, D. R., \& Mohammed, S. A. (2009). Discrimination and racial disparities in health: Evidence and needed research. Journal of Behavioral Medicine, 32, 20-47. http://dx.doi.org/10.1007/s10865-008-9185-0

Williams, D. R., Yu, Y., Jackson, J. S., \& Anderson, N. B. (1997). Racial differences in physical and mental health: Socioeconomic status, stress and discrimination. Journal of Health Psychology, 2(3), 335-351. http://dx.doi.org/10.1177/135910539700200305 